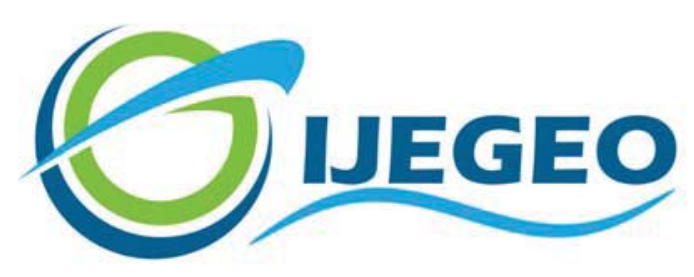

International Journal of Environment and Geoinformatics (IJEGEO) is an international, multidisciplinary, peer reviewed, open access journal.

\title{
Determination of spectral and broadband albedos in visible-near infrared bands for different phenophases of wheat using hemispherical directional reflectance measurements
}

\author{
Manoj M. LUNAGARIA
}

\author{
Chief in Editor \\ Prof. Dr. Cem Gazioğlu \\ Co-Editors \\ Prof. Dr. Dursun Zafer Şeker, Prof. Dr. Şinasi Kaya, \\ Prof. Dr. Ayşegül Tanık and Assist. Prof. Dr. Volkan Demir
}

Editorial Committee (December 2021)

Assoc. Prof. Dr. Abdullah Aksu (TR), Assit. Prof. Dr. Uğur Algancı (TR), Prof. Dr. Bedri Alpar (TR), Assoc. Prof. Dr. Aslı Aslan (US), Prof. Dr. Levent Bat (TR), Prof. Dr. Paul Bates (UK), İrşad Bayırhan (TR), Prof. Dr. Bülent Bayram (TR), Prof. Dr. Luis M. Botana (ES), Prof. Dr. Nuray Çağlar (TR), Prof. Dr. Sukanta Dash (IN), Dr. Soofia T. Elias (UK), Prof. Dr. A. Evren Erginal (TR), Assoc. Prof. Dr. Cüneyt Erenoğlu (TR), Dr. Dieter Fritsch (DE), Prof. Dr. Çiğdem Göksel (TR), Prof.Dr. Lena Halounova (CZ), Prof. Dr. Manik Kalubarme (IN), Dr. Hakan Kaya (TR), Assist. Prof. Dr. Serkan Kükrer (TR), Assoc. Prof. Dr. Maged Marghany (MY), Prof. Dr. Michael Meadows (ZA), Prof. Dr. Nebiye Musaoğlu (TR), Prof. Dr. Masafumi Nakagawa (JP), Prof. Dr. Hasan Özdemir (TR), Prof. Dr. Chryssy Potsiou (GR), Prof. Dr. Erol Sarı (TR), Prof. Dr. Maria Paradiso (IT), Prof. Dr. Petros Patias (GR), Prof. Dr. Elif Sertel (TR), Prof. Dr. Nüket Sivri (TR), Prof. Dr. Füsun Balık Şanlı (TR), Prof. Dr. Uğur Şanlı (TR), Duygu Ülker (TR), Prof. Dr. Seyfettin Taş (TR), Assoc. Prof. Dr. Ömer Suat Taşkın (TR), Assist. Prof. Dr. Tuba Ünsal (TR), Dr. Manousos Valyrakis (UK), Dr. İnese Varna (LV), Dr. Petra Visser (NL), Prof. Dr. Selma Ünlü (TR), Assoc. Prof. Dr. Oral Yağcı (TR), Prof. Dr. Murat Yakar (TR), Assoc. Prof. Dr. İ. Noyan Yılmaz (AU); Assit. Prof. Dr. Sibel Zeki (TR)

Abstracting and Indexing: TR DIZIN, DOAJ, Index Copernicus, OAJ, Scientific Indexing Services, International Scientific Indexing, Journal Factor, Google Scholar, Ulrich's Periodicals Directory, WorldCat, DRJI, ResearchBib, SOBIAD 


\title{
Reaserch Article
}

\section{Determination of spectral and broadband albedos in visible-near infrared bands for different phenophases of wheat using hemispherical directional reflectance measurements}

\author{
Manoj M. Lunagaria \\ Anand Agricultural University, Department of Agricultural Meteorology, BACA, Anand-388110, INDIA
}

Received 07.01.2021

Accepted 21.08.2021

E-mail: mlunagaria@gmail.com

How to cite: Lunagaria (2021). Determination of spectral and broadband albedos in visible-near infrared bands for different phenophases of wheat using hemispherical directional reflectance measurements. International Journal of Environment and Geoinformatics (IJEGEO), 8(4): 460-466. DOI: 10.30897/ijegeo. 855633.

\begin{abstract}
Albedo is an important parameter in radiation balance, energy balance, atmospheric correction of remote sensing data and weather forecasting models. The values of albedo of agricultural area vary with changes in biophysical parameters at different phenophases of the crop. Spectral and broadband albedo of visible-infrared bands for wheat canopy was estimated with numerical and spectral integration of hemispherical directional reflectance factors (HDRFs). The HDRF measurements on wheat were acquired at 54 view angles ( 6 azimuthal planes $\times 9$ view zenith angles) to cover the hemispheric span up to $60^{\circ}$ view zenith at 7-8 days' interval during early growth stages to physiological maturity. Canopy and atmospheric parameters were measured parallel to HDRFs of the crop. The spectral and broadband albedo of wheat varies in decreasing pattern with advancement of growth stages. Visible-infrared albedo of crop was maximum at early growth stages (tillering and booting; 0.23) and minimum at late growth stages (late milking and dough; 0.15). The albedo values retrieved from HDRF in this investigation can be useful for phenophase specific applications in cropland fluxes algorithms, crop phenotyping, regional climate modeling and other remote sensing studies.
\end{abstract}

Keywords: albedo, HDRF, multiangle remote sensing, phenophase, wheat

\section{Introduction}

Albedo is the key radiometric quantity parameter that plays an important role in radiation balance studies and atmospheric general circulation models. Albedos of the natural surfaces are governing parameters of the energy budget of the area. Climate models need surface albedo values with very small absolute error (Sellers, 1993; Jin et al.,2003). Meanwhile, albedo values over vegetated surfaces like agricultural areas depend on crop grown and its growth phase. Crop canopy albedo can be also useful to determine water use by transpiration (Blum, 2005), climate change mitigation in geoengineering approach (Carrer et al., 2018; Ridgwell et al., 2009; Singarayer et al. 2009; Imamoğlu and Sertel, 2016; Ülker et al., 2018), energy balance algorithms, crop phenotyping and parameterization of cropland energy fluxes. Canopy albedo reported to vary with genetic variation in many studies (Serban et al. 2012; Febrero et al. 1998; Hatfield and Carlson, 1979). Crop breeding efforts to increase crop albedo can help to improve crop performance in drought and heat stress conditions by reducing transpiration and canopy temperature. Crops like wheat go through distinct canopy architectural changes during crop life cycle and markedly influence the canopy reflectance and its anisotropy (Lunagaria and Patel, 2017). The spectral albedo strongly depends on crop type, age of the crop and season (Iqbal, 1983). So, crop phenophase specific albedo values can be useful to studies on radiation and energy balance, evapotranspiration flux estimation, regional climate modeling, climate change biogeoengineering, atmospheric correction of remote sensing data and crop stress detection.

On the ground, broadband albedo can be measured by albedometer, consisting upward looking and inverted pyranometers. Albedo measurements using airborne and spaceborne platforms cannot be used for accurate measurements for small surfaces (Pinty et al. 2001). Besides, most of these sensors measure albedo at discrete wavebands. Also, most natural surfaces like crop canopies behave as non- Lambertian reflector. So, remote sensing estimated albedos using a single nadir or off-nadir angle observations which do not represent true albedo. Kimes and Sellers (1985) reported that albedo estimated from nadir gave error as great as $45 \%$ as compared to estimates from multi-angle observations. Thus, the 'true' albedos can be derived using bidirectional reflectance distribution function (BRDF) and the albedos are mathematically defined as weighted integrals of the BRDF (Wanner et al.,1997). The broadband albedo is further integration of the spectral albedo over the spectral range.

Ranson et al. (1991) have computed albedo of bluegrass field and bare soil (fine-loamy, mixed, mesic Fluvaquentic Dystrochrept) from the spectral 
bidirectional reflectance factor (BRF) measurements by two techniques; numeric integration and fitting of an empirical equation. Peltoniemi et al. (2010) computed land surface hemispherical albedos of several targets using the BRF library of the Finnish Geodetic Institute (FGI). Some other researchers (Jacob et al. 2002; Eck and Deering, 1998; Irons et al.,1988) also used groundbased, airborne and spaceborne multiband BRF data to compute albedo of agricultural targets.

This paper is aimed to compute spectral and broadband albedo values of wheat canopy at different phenophases in visible-near infrared (VNIR) spectral range using hemispherical directional reflectance measurements. Wheat crop was considered in this study as the crop has large acreage than any other crop over the world. The canopy architecture of wheat changes dramatically at different phenophases during life cycle (Lunagaria and Patel, 2017) of the crop and leads to change in albedo. Thus, evaluation of magnitude of changes in albedo with changes in canopy parameters at different phenophases of wheat is attempted in the study.

\section{Materials and Methods Experimental setup}

A field goniometer resembling well-known FIGOS (FIeld GOniometer System; Sandmeier and Itten, 1999) with $4 \mathrm{~m}$ diameter installed at Anand Agricultural University, Anand $\left(22.538{ }^{\circ} \mathrm{N}\right.$ Latitude, $72.981{ }^{\circ} \mathrm{E}$ Longitude, $45.1 \mathrm{~m}$ above mean sea level) was used for spectrodirectional measurements. According to Schaepman-Strub et al. (2006), in-situ measurement under clear sky condition is hemispherical directional

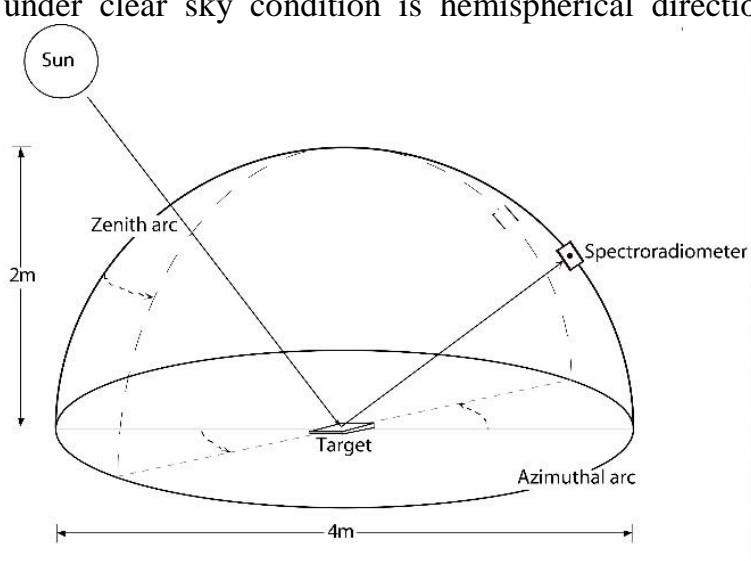

reflectance factor (HDRF) as BRF involves infinitesimal small quantities and cannot be measured. Though, BRF term is also established in literature and erroneously used in many studies (Sandmeier and Itten, 1999; Chopping, 2000; Susaki, et al. 2004). Wheat (Triticum aestivum L.) crop (cultivar Gujarat Wheat 496) was chosen as target crop and sown in circular plot of $5 \mathrm{~m}$ diameter under the field goniometer (Figure 1) during November to April months of year 2011-2012. Row effect in directional observations is prominent in line sown agricultural crops due to azimuthal asymmetry (Lucht and Roujean, 2000). Meanwhile, line sowing is most common in wheat growing regions and row spacing $22.5 \mathrm{~cm}$ is recommended spacing for wheat at most parts of India. Wheat has shallow root system and individual plant stand in broadcasting results in lodging particularly in sandy loam soil at experimental region. So, azimuthal symmetry was achieved by sowing the crop in concentric rows with row spacing $22.5 \mathrm{~cm}$.

\section{Measurements}

Hemispherical directional reflectance observations were acquired by mounting spectroradiometer FieldSpec HandHeld (Analytical Spectral Devices, Inc., USA) with a $3.5^{\circ}$ instantaneous field of view (IFOV) on the field goniometer system. The spectrodirectional measurements were acquired in a spectral range of 325 $\mathrm{nm}$ to $1075 \mathrm{~nm}$ with a spectral resolution of $1.0 \mathrm{~nm}$. The IFOV of $3.5^{\circ}$ projects circular GIFOV (Ground projected instantaneous field of view) of $12.22 \mathrm{~cm}$ diameter at nadir. With an increase of view zenith angle, GIFOV becomes elliptical and extent increase towards foreword direction.

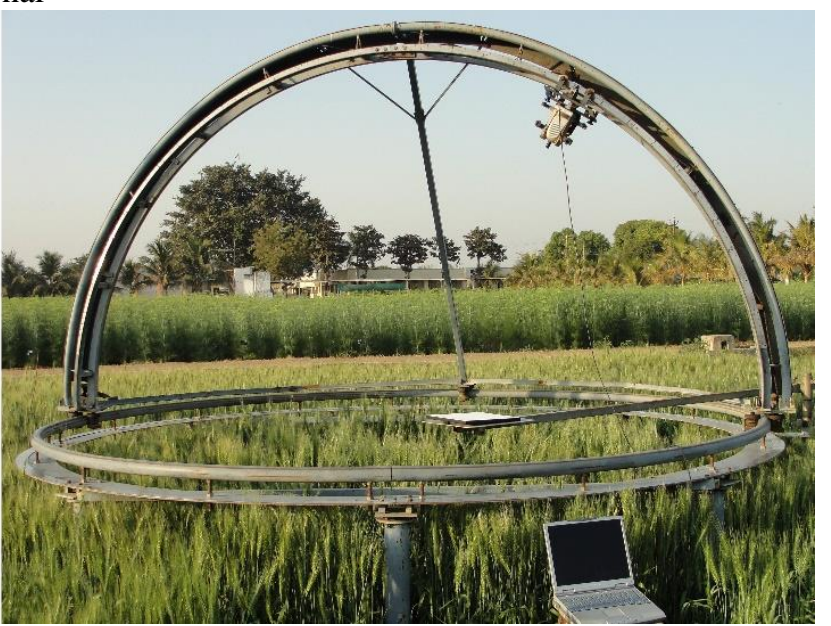

Figure 1. Schematics of the spectro-goniometer setup.

The GIFOV $(24.5 \mathrm{~cm})$ was maximum at $60^{\circ}$ view zenith angle along the azimuthal plane of observation. In all instances, the spactroradiometer observes only $12.22 \mathrm{~cm}$ arc of the circular wheat rows so the effect of a circular plant stand will be negligible. To scan hemispheric coverage, HDRFs were measured with this spectrogoniometeric setup at resolutions of $30^{\circ}$ and $15^{\circ}$ in azimuth $(\varphi)$ and zenith $(\theta)$ angles, respectively at time around solar noon (12:38) on clear and haze-free days. To ascertain clear atmosphere, aerosol optical thickness and columnar water were monitored using Microtops II ${ }^{\circledR}$
Sunphotometer. In case of albedo measurement under such prominent direct illumination, HDRF observation approximate BRF and the albedo can be referred as 'black sky albedo' (Lucht et al., 2000). The measurements were made at 7-8 days' interval from early growth stage (tillering) to dough stage of wheat. Comprehensive methodology and phenophase wise results on reflectance anisotropy using these data sets are explained in Lunagaria and Patel, 2017. Illumination geometry (solar zenith $\left(\theta_{\mathrm{i}}\right)$ and azimuth $\left(\varphi_{\mathrm{i}}\right)$ angles) for the experimental site was computed with algorithm 
given in Reda and Andreas (2003). Canopy biophysical parameters (chlorophyll, mean leaf inclination angle, LAI, and plant height) were measured parallel to spectrodirectional measurements. Chlorophyll was measured by SPAD meter (TYS-A; Zhejiang Top Instrument Co., Ltd., Zhejiang, China) and the nondimensional SPAD converted to $\mu \mathrm{g} \mathrm{cm}^{-2}$ by calibration coefficients of the meter (Lunagaria et al. 2015). LAI2000 Plant Canopy Analyser (LI-COR, USA) was used to measure LAI and mean leaf tilt angle nondestructively. Plant height was measured with ruler scale.

\section{Computation of albedo using HDRF}

Surface albedo is defined as the fraction of incident solar radiation reflected both in all directions above the surface and over the whole solar spectrum (Pinty and Verstraete, 1992). So, albedo is the ratio of total radiance reflected by a surface in any direction within the surrounding hemisphere to the total incoming irradiance. The spectral albedo $\alpha_{\lambda}$ can be computed by the integration of the observed HDRF $\rho\left(\lambda, \theta_{\mathrm{s}}, \varphi_{\mathrm{s}}, \theta_{\mathrm{r},} \varphi_{\mathrm{r}}\right)$ over the hemisphere (Kimes and Seller, 1985; Sandmeier and Itten, 1999).

$\alpha_{\lambda}$

$=\frac{1}{\pi} \int_{0}^{2 \pi} \int_{0}^{\frac{\pi}{2}} \rho\left(\lambda, \theta_{\mathrm{s}}, \varphi_{\mathrm{s}}, \theta_{\mathrm{r}}, \varphi_{\mathrm{r}}\right) \cos \theta_{\mathrm{r}} \sin \theta_{\mathrm{r}} \mathrm{d} \theta_{\mathrm{r}} \mathrm{d} \varphi_{\mathrm{r}}$

Where, $\theta$ is zenith angle and $\varphi$ is azimuth angle. Subscript $\mathrm{s}$ is for solar and $\mathrm{r}$ is for remote sensor. To estimate $\alpha_{\lambda}$ from HDRFs, numerical integration was performed over the full range of hemispheric coverage involving eleven view zenith angles and six azimuth angles (Figure 2). The method is adopted after Irons et al.,1988, Ranson et al., 1991 and Grover et al.,2000 as:

$$
\alpha_{\lambda}=\frac{1}{\pi} \sum_{j=1}^{6} \rho\left(\lambda_{i}, \theta_{j}\right) \Delta \Omega_{j}
$$

Where, $\lambda_{i}$ is a wavelength from spectral range $325 \mathrm{~nm}$ to $1075 \mathrm{~nm}$ and $\Delta \Omega_{j}$ is the projected solid angle of the partition of the $2 \pi$ sterdian angle. The hemisphere (represented as $2 \pi$ sterdian solid angle) has been partitioned into six solid angles which project as annular rings on the horizontal surface (Figure 2). So, annular rings represent the discrete portion of the projected solid angle $(\Delta \Omega)$ with the representing measurement points for each azimuth angle. Each $\mathrm{j}^{\text {th }}$ angle can be envisioned as a hollow out cone defined by range of zenith angles.

$$
\Delta \Omega_{j}=\pi\left(\sin ^{2} \theta_{j}-\sin ^{2} \theta_{j-1}\right)
$$

Where, $\theta_{j}$ is the zenith angles $\left(0^{\circ}, 7.5^{\circ}, 22.5^{\circ}, 37.5^{\circ}, 52.5^{\circ}, 65.7^{\circ}, 90^{\circ}\right)$ for $j=1,2,3,4,5,6$, 7.

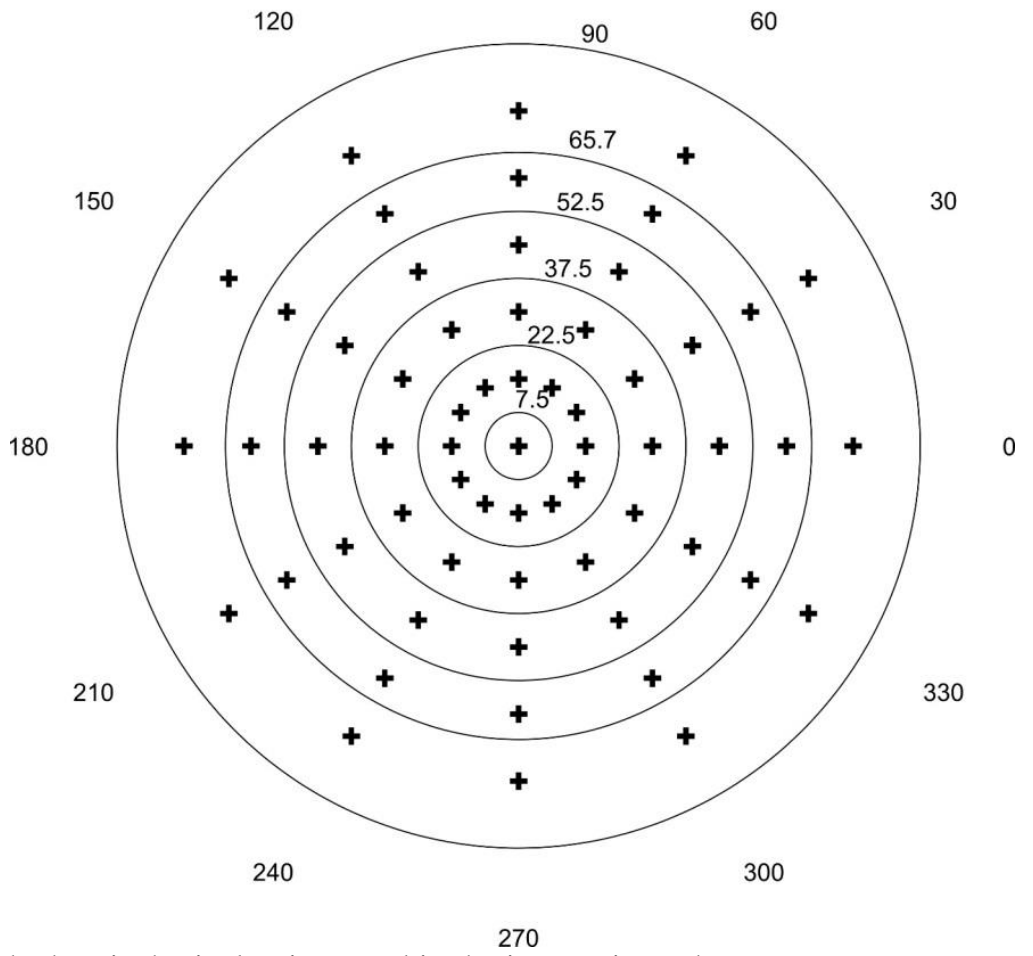

270

Figure 2. Projection of the hemispherical points used in the integration scheme.

Each projected solid angle was multiplied by the mean HDRF within the solid angle (i.e. mean of HDRFs measured in a particular annular ring of solid angle; Figure 2).

$$
\bar{\rho}_{j}=\sum_{k=1}^{m} \frac{\rho\left(\lambda_{i}, \theta_{j}^{*}, \varphi_{k}\right)}{m}
$$

Where $\theta_{j-1}<\theta_{j}^{*}<\theta_{j}, m$ is the number of HDRF values (12) in the respective annular solid angle ring. Mean HDRF $\left(\bar{\rho}_{j}\right)$ of twelve HDRF values $(m)$ were used in each annular rings except the innermost ring $\left(\Delta \Omega_{1}\right)$ as the measurements were acquired in six azimuthal planes. Six nadir HDRF measurements were averaged for the innermost ring. The annular rings represent the discrete 
portion of the projected solid angle $(\Delta \Omega)$ with measurement points for each azimuth planes. The HDRFs for the outermost ring (between zenith angles $65.7^{\circ}$ to $90^{\circ}$ ) were extrapolated using spline interpolation from the measured values (ranging from forward $60^{\circ}$ to backward $60^{\circ}$ ) of the same azimuthal plane. Thus, the spectral albedo was computed as a product of $\bar{\rho}_{j}$ and $\Delta \Omega_{j}$ summed over the eleven solid angles. Since, mathematically the albedo is irradiance weighted integral (average) of the BRDF (Wanner et al., 1997). Solar irradiance flux weighted numerical integration of the spectral albedo $\left(\alpha_{\lambda}\right)$ over the visible spectral range was performed for narrowband to broadband albedo $\left(\alpha_{\lambda_{i}}^{\lambda_{n}}\right)$ conversion. Broadband albedo values for different wavebands were computed by defining wavelength intervals $\left(\lambda_{i}\right.$ to $\left.\lambda_{n}\right)$ for spectral integration.

$$
\alpha_{\lambda_{i}}^{\lambda_{n}}=\frac{\sum_{i=1}^{n} \alpha_{\lambda_{i}} S_{i}}{\sum_{i=1}^{n} S_{i}}
$$

Where, $S_{i}$ is solar irradiance flux of the wavelength $\lambda_{i}$. Downwelling solar irradiance flux for the spectral range of $325 \mathrm{~nm}$ to $1075 \mathrm{~nm}$ was computed using the SBDART (Santa Barbara DISORT Atmospheric Radiative Transfer) model (Ricchiazzi et al., 1998) for time of hemispherical directional reflectance measurements. Measured aerosol optical thickness and water column were used as inputs of SBDART to simulate solar irradiance spectrum for the time of observations. A more accurate MODTRAN 3 solar spectrum was selected in SBDART.

\section{Results and discussion \\ Canopy parameters and irradiance}

The surface albedo depends on the solar zenith and the three-dimensional structure of vegetation canopy (Yang, et al., 2001; Schaaf et al., 2002). Measured canopy biophysical parameters, soil moisture status and solar zenith angle at the time of observations are given in Table 1 for phenophases of wheat. There was less than $7^{\circ}$ change in solar azimuth angle during HDRF measurements acquired in 17-20 minutes near solar noon. Solar zenith of time of observation in a day was changed about $10^{\circ}$ during the observed growth stages in the crop cycle. Irradiance flux spectra for the location and the time of HDRF observations were simulated and used for narrowband to broadband albedo conversion. The mean irradiance flux with standard deviation is depicted in Figure 3.

Table 1. Total chlorophyll, leaf area index, leaf angle, crop height, and soil moisture status at different phenophases of wheat.

\begin{tabular}{clccccc} 
No. & Phenophase & $\begin{array}{c}\text { Chlorophyll }(\mu \mathrm{g} \\
\left.\mathrm{cm}^{-2}\right)\end{array}$ & LAI & $\begin{array}{c}\text { Mean leaf } \\
\text { angle }\left({ }^{\circ}\right)\end{array}$ & $\begin{array}{c}\text { Height } \\
(\mathrm{cm})\end{array}$ & $\begin{array}{c}\text { Soil moisture } \\
(\%)\end{array}$ \\
\hline 1 & Tillering & 36.9 & 3.93 & 48 & 46 & 4.2 \\
2 & Booting & 41.9 & 4.49 & 52 & 53 & 6.5 \\
3 & Heading & 44.9 & 4.71 & 56 & 85 & 3.5 \\
4 & Flowering & 46.0 & 4.96 & 55 & 95 & 9.0 \\
5 & Early Milking & 44.1 & 4.52 & 58 & 96 & 2.8 \\
6 & Late Milking & 50.8 & 4.10 & 58 & 96 & 3.1 \\
7 & Dough & 47.5 & 3.35 & 58 & 96 & 6.4 \\
\hline
\end{tabular}

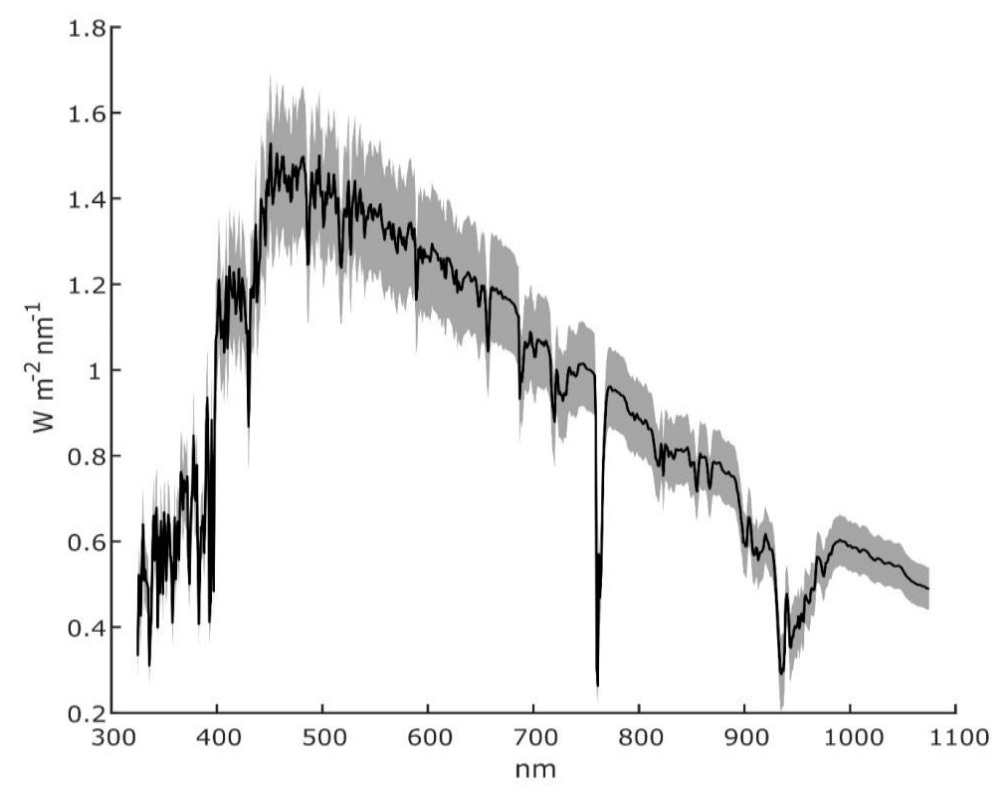

Figure 3. SBDART simulated downwelling irradiance flux at the time of hemispherical directional measurements during different phenophases of wheat. Dark line is mean spectra with standard deviation representing all simulations for different time of observations. 
The canopy parameters show prominent changes at different phenophases during the wheat life cycle. This clearly indicates that a single albedo value may not be valid to represent changing reflectance magnitude and its anisotropy at different stages of crop life.

\section{Spectral albedo $\left(\alpha_{\lambda}\right)$}

The spectral albedos derived from HDRF measurements for different growth stages of wheat are depicted in
Figure 4. Spectral albedos of tillering and booting phases were nearly identical except in green and near-infrared (NIR) wavelengths. At these phenophases, albedo values were also maximum for blue, green and NIR. The spectral albedos at these phases might be result of low transmission from relatively horizontally distributed (leaf angle $48^{\circ}-50^{\circ}$ ) canopy with low photosynthetic absorption (chlorophyll $36.9 \mu \mathrm{g} \mathrm{cm}^{-2}$ ).

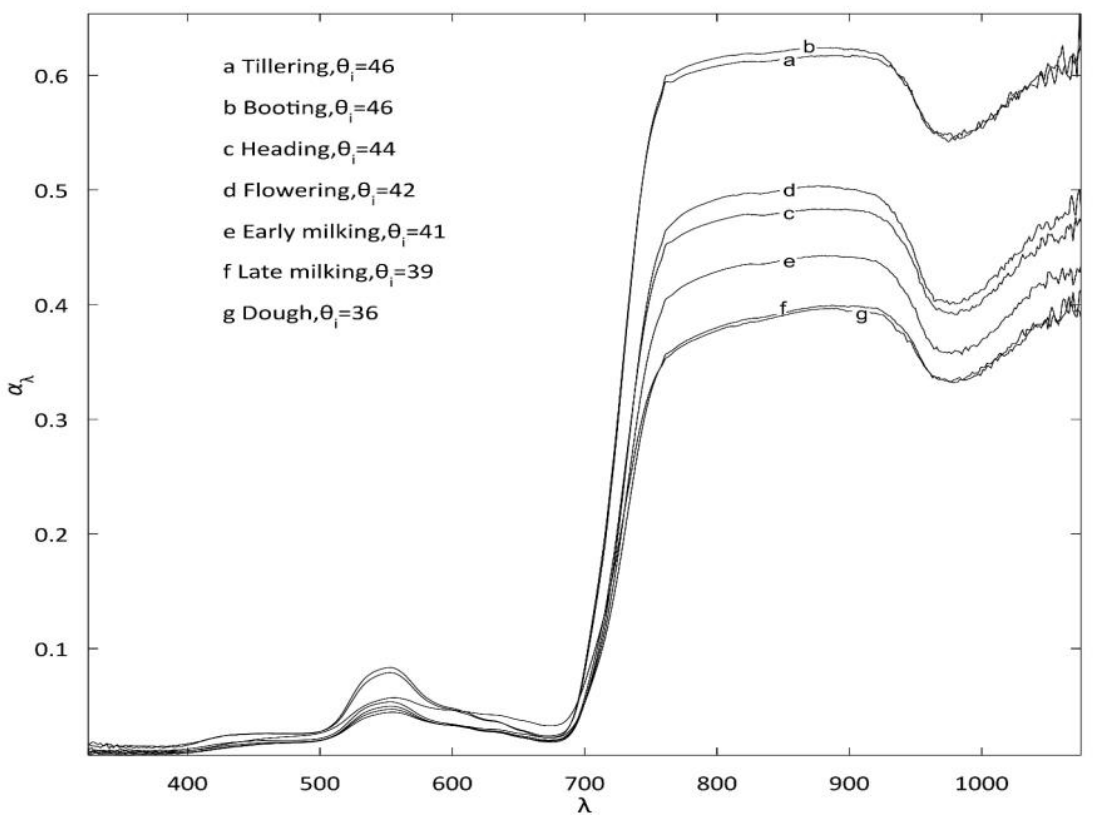

Figure 4. The spectral albedo of wheat at different phenological phases.

Table 2. Spectral albedo of optimal hyperspectral bands at phenophases of the wheat.

\begin{tabular}{lccccccc}
\hline \multicolumn{1}{c}{$\alpha_{\lambda}$} & Tillering & Booting & Heading & Flowering & $\begin{array}{l}\text { Early } \\
\text { Milking }\end{array}$ & Late Milking & Dough \\
\hline$\alpha_{490}$ (blue) & 0.026 & 0.026 & 0.020 & 0.019 & 0.018 & 0.018 & 0.024 \\
$\alpha_{520}$ (green 1) & 0.049 & 0.046 & 0.034 & 0.032 & 0.031 & 0.030 & 0.038 \\
$\alpha_{550}$ (green 2) & 0.083 & 0.079 & 0.053 & 0.049 & 0.047 & 0.044 & 0.056 \\
$\alpha_{575}$ (green 3) & 0.063 & 0.060 & 0.042 & 0.04 & 0.039 & 0.038 & 0.051 \\
$\alpha_{660}$ (red 1) & 0.025 & 0.026 & 0.021 & 0.021 & 0.022 & 0.024 & 0.035 \\
$\alpha_{675}$ (red 2) & 0.023 & 0.024 & 0.019 & 0.018 & 0.020 & 0.022 & 0.033 \\
$\alpha_{700}$ (red edge 1) & 0.083 & 0.079 & 0.057 & 0.053 & 0.053 & 0.052 & 0.070 \\
$\alpha_{720}$ (red edge 2) & 0.246 & 0.239 & 0.166 & 0.157 & 0.144 & 0.133 & 0.156 \\
$\alpha_{845}$ (NIR) & 0.613 & 0.620 & 0.479 & 0.499 & 0.437 & 0.391 & 0.389 \\
$\alpha_{905}$ (NIR peak 1) & 0.617 & 0.622 & 0.482 & 0.500 & 0.441 & 0.399 & 0.395 \\
$\alpha_{920}$ (NIR peak 2) & 0.614 & 0.619 & 0.478 & 0.495 & 0.438 & 0.397 & 0.392 \\
$\alpha_{975}$ (NIR moisture & 0.549 & 0.542 & 0.393 & 0.401 & 0.359 & 0.333 & 0.333 \\
sensitive) & & & & & & & \\
\hline
\end{tabular}

There was a marked decrease in spectral albedo of the NIR spectra as the booting stage approached and earhead emergence occurred. This was in accord with the prominent increase in canopy height $(53 \mathrm{~cm}$ at booting to $85 \mathrm{~cm}$ at heading) and increase of leaf angle (from $52^{\circ}$ to $\left.56^{\circ}\right)$ and chlorophyll $\left(41.9 \mu \mathrm{g} \mathrm{cm}^{-2}\right.$ to $\left.44.9 \mu \mathrm{g} \mathrm{cm}^{-2}\right)$. The spectral albedo was found to decrease gradually during peak vegetative growth stages, particularly in NIR wavelengths. Similar to early growth stages, late milking stage and dough stage also showed identical NIR albedo pattern. Red band at the dough stage showed the high spectral albedo values as the photosynthetic absorption decreased with senescence. The decline in chlorophyll content from late milking to dough $\left(50.8 \mu \mathrm{g} \mathrm{cm}^{-2}\right.$ to 47.5 $\mu \mathrm{g} \mathrm{cm}^{-2}$ ) also in agreement with this result. Optimal hyperspectral bands for agricultural crop characterization has been determined by Thenkabail et al. (2002). The spectral albedos at the central wavelengths of these optimal spectral bands are given in Table 2 for different wheat growth stages.

\section{Broadband albedo}

The broadband albedo values were computed for blue, green, red and NIR bands as well as full VNIR (325nm$1075 \mathrm{~nm}$ ) spectral region (Table. 3). The broadband albedos for all bands showed a decreasing pattern with 
advancement of the growth stages from early growth stages to milking stage. In general, the trend pattern is inverse to the chlorophyll content and canopy structure parameters (LAI, leaf angle and plant height) recorded at different phenophases (Table 1).

Table 3. Broadband albedos at different phenophases of wheat for blue, green, red and NIR bands as well as complete VNIR spectral region.

\begin{tabular}{cccccccc}
\hline$\alpha_{\lambda_{i}}^{\lambda_{n}}$ & Tillering & Booting & Heading & Flowering & $\begin{array}{l}\text { Early } \\
\text { Milking }\end{array}$ & $\begin{array}{l}\text { Late } \\
\text { Milking }\end{array}$ & Dough \\
\hline $\begin{array}{c}\alpha_{325}^{520} \\
(\text { blue })\end{array}$ & 0.024 & 0.024 & 0.018 & 0.016 & 0.015 & 0.015 & 0.019 \\
$\begin{array}{c}\alpha_{521}^{620} \\
\text { (green) }\end{array}$ & 0.063 & 0.060 & 0.042 & 0.040 & 0.039 & 0.038 & 0.050 \\
$\begin{array}{c}\alpha_{621}^{690} \\
(\text { red) }\end{array}$ & 0.030 & 0.030 & 0.024 & 0.023 & 0.024 & 0.026 & 0.038 \\
$\begin{array}{c}\alpha_{691}^{1075} \\
(\text { NIR })\end{array}$ & 0.525 & 0.527 & 0.398 & 0.410 & 0.362 & 0.327 & 0.329 \\
$\begin{array}{c}\alpha_{325}^{1075} \\
(\text { VNIR })\end{array}$ & 0.232 & 0.231 & 0.174 & 0.176 & 0.158 & 0.147 & 0.150 \\
\hline
\end{tabular}

The broadband albedo values were found to rise relatively in red and green bands at the dough stage. As the VNIR albedometer/sensor was not available to measure direct albedo values parallel to spectrodirectional measurements, computed broadband albedos were not validated.

\section{Conclusions}

Hemispherical directional reflectance (HDRF) measurements of wheat canopy were acquired during the crop growth cycle using field spectrogoniometeric setup. Measurements of crop growth parameters, soil moisture and atmospheric condition were also made parallel to the HDRFs. Spectral HDRF measurements and simulated irradiance flux were used to compute spectral and broadband albedos for different phenophases of wheat. Spectral albedos of wheat canopy decrease gradually with changes in canopy parameters with advancement of phenophases, particularly in NIR. Early growth (tillering and booting phases) and late growth stages (milking and dough phases) show identical NIR albedo patterns. The broadband albedos values for all bands showed decrease with advancement of phenophases from early growth stages to milking stage. The VNIR albedo of wheat is maximum at early growth stages (tillering and booting; 0.23 ) and minimum at late growth stages (late milking and dough; 0.15). Phase wise albedos can be used for surface flux algorithms of wheat field, wheat phenotyping, regional climate models and wheat modeling.

\section{Acknowledgements}

Author thankful to Dr. V. N. Sridhar and Dr. N. K. Patel, retired scientists of ISRO, who initiated experiments on multiangular remote sensing and setup the goniometer facility at Anand. Special thanks to Dr. M. R. Pandya, Scientist, ISRO for suggestions and help. Mr. Suresh Padhiyar, Met Observer is acknowledged for his assistance in spectrodirectional measurements.

\section{References}

Blum, A.(2005). Drought resistance, water-use efficiency, and yield potential - are they compatible, dissonant, or mutually exclusive? Australian Journal of Agricultural Research, 56: 1159-1168.

Carrer, D., Pique, G., Ferlicoq, M., Ceamanos, X. Ceschia, E.(2018). What is the potential of cropland albedo management in the fight against global warming? A case study based on the use of cover crops, Environmental Research Letters, 13, 044030, DOI: 10.1088/1748-9326/aab650

Chopping, M. J.(2000). Testing a LiSK BRDF model with in situ bidirectional reflectance factor measurements over semiarid grasslands, Remote Sensing of Environment, 74, 287-312.

Eck, T.F., Deering, D.W.(1998). Estimation of total albedo from spectral hemispheric reflectance for steppe grassland, Remote Sensing Reviews, 17:1-4, 133-148.

Febrero, A., Santiago Fernandez, S., Molina-Cano, J.L. and Araus, J.L.(1998). Yield, carbon isotope discrimination, canopy reflectance and cuticular conductance of barley isolines of differing glaucousness. Journal of Experimental Botany, 49 (326): 1575-1581.

Grover, K. D., Steven, M. D., Rondeaux, G.(2000). Estimating albedo from limited spectral and angular data. International Journal of Remote Sensing, 21(1):155-165.

Hatfield, J.L., Carlson, R.E.(1979). Light quality distributions and spectral albedo of three maize canopies. Agricultural Meteorology, 20 (3): 215-226.

İmamoğlu, M , Sertel, E . (2016). Analysis of Different Interpolation Methods for Soil Moisture Mapping Using Field Measurements and Remotely Sensed Data, International Journal of Environment and Geoinformatics, 3(3), 11-25.doi.10.30897/ ijegeo.306477

Iqbal, M.(1983). An introduction to solar radiation. Academic press, Toronto.

Irons, J.R., Ranson, K. J., Daughtry, C. S. T.(1988). Estimating Big Bluestem Albedo from Directional 
Reflectance Measurements. Remote Sensing of Environment, 25:185-199.

Jacob, F., Olioso, A., Weiss, M., Baret, F., Hautecoeur, O.(2002). Mapping short-wave albedo of agricultural surfaces using airborne PolDER data. Remote Sensing of Environment, 80: 36- 46.

Jin, Y., Schaaf, C.B., Woodcock, C.E., Gao, F., Li, X., Strahler, A.H., Lucht, W., Liang, S.(2003). Consistency of MODIS surface bidirectional reflectance distribution function and albedo retrievals: 2. Validation. J. Geophys. Res., 108, doi:10.1029/2002JD002804.

Kimes, D.S., Sellers, P.J.(1985). Inferring hemispherical reflectance of the earth's surface for global energy budgets from remotely sensed nadir of directional radiance values. Remote Sensing of Environment, 18:205-223

Lucht, W., Roujean, J.L.(2000). Considerations in the parametric modeling of BRDF and albedo from multiangular satellite sensor observations, Remote Sensing Reviews, 18, 343-379.

Lucht, W., Schaaf, C.B., Strahler, A.H.(2000). An algorithm for the retrieval of albedo from space using semiempirical BRDF models. IEEE Transactions on Geoscience and Remote Sensing, 38(2), 977-998.

Lunagaria, M. M., Patel, H. R.(2017). Changes in reflectance anisotropy of wheat crop during different phenophases. International Agrophysics, 31, 203218. doi: 10.1515/intag-2016-0045.

Lunagaria, M. M., Patel, H. R., Pandey, V.(2015). Evaluation and calibration of noninvasive leaf chlorophyll meters for wheat. Journal of Agrometeorology, 17(1), 51-54.

Peltoniemi, J. I., Manninen, T., Suomalainen, J., Hakala, T., Puttonen, E., Riihelä, A.(2010). Land Surface Albedos Computed from BRF Measurements with a Study of Conversion Formulae, Remote Sensing, 2:1918-1940.

Pinty, B., Verstraete, M.(1992). On the design and validation of surface bidirectional reflectance and albedo model. Remote Sensing of Environment, 41:155- 167.

Pinty, B., Verstraete, M.M., Gobron, N., Roveda, F., Govaerts, Y., Martonchik, J.V., Diner, D.J., Kahn, R.A.(2001). Exploitation of surface albedo derived from the Meteosat data to characterize land surface changes. Proceedings of the Geoscience and Remote Sensing Symposium, IGARSS'01, IEEE 2001, International Sydney, NSW, 5: 2250-2252.

Ranson, K. J., Irons, J. R. and Daughtry, C. S. T.(1991). Surface albedo from bidirectional reflectance. Remote Sensing of Environment, 35: 201-211.

Reda, I. and Andreas, A.(2003). Solar position algorithm for solar radiation application. National Renewable Energy Laboratory (NREL) Technical report NREL/TP-560-34302.

Ricchiazzi, P., S. R. Yang, C. Gautier, Sowle, D. (1998). SBDART: A research and teaching software tool for plane-parallel radiative transfer in the Earth's atmosphere. Bulletin of American Meteorological Society, 79:2101 - 2114.
Ridgwell, A., Singarayer, J.S., Hetherington, A.M., Valdes, P.J.(2009). Tackling regional climate change by leaf albedo bio-geoengineering. Current Biology, 19: 1-5.

Sandmeier, S. R., Itten, K. I.(1999). A Field Goniometer System (FIGOS) for acquisition of hyperspectral BRDF data. IEEE Transactions on Geoscience and Remote Sensing, 37(2):978-986.

Schaaf, C. B., F. Gao, A. H. Strahler, W. Lucht, X. Li, T. Tsang, N. C. Strugnell, X. Zhang, Y. Jin, J.-P. Muller, P. Lewis, M. Barnsley, P. Hobson, M. Disney, G. Roberts, M. Dunderdale, C. Doll, R. d'Entremont, B. Hu, S. Liang, Privette, J. L. (2002). First Operational BRDF, Albedo and Nadir Reflectance Products from MODIS, Remote Sensing of Environment, 83: 135-148

Schaepman-Strub G., Schaepman M.E., Painter T.H., Dangel S., Martonchik J.V.(2006). Reflectance quantities in optical remote sensing - Definitions and case studies Remote Sensing of Environment, 103: 27-42

Sellers, P. J.(1993). Remote sensing of the land surface for studies of global change, NASA/GSFC Int. Satell. Land Surface Climatol. Proj. Rep., Columbia, MD.

Şerban, G., Cotfas, D.T., Cotfas, P. A. (2012). Crop albedo measurements after anthesis reveal significant differences among Romanian wheat cultivars. Romanian Agricultural Research, 29:39-43.

Singarayer, J. S., Ridgwell, A., Irvine, P.(2009). Assessing the benefits of crop albedo biogeoengineering. Environmental Research Letters. 4: 045110

Susaki, J., Hara, K., Park, J.,Yasuda, Y., Kajiwara, K. Honda, Y.(2004). Validation of temporal BRDFs of paddy fields estimated from MODIS reflectance data, IEEE Transactions on Geoscience and Remote Sensing, 42, 1262-1270.

Thenkabail, P.S., R.B. Smith., De Pauw, E. (2002). Evaluation of narrowband and broadband vegetation indices for determining optimal hyperspectral wavebands for agricultural crop characterization. Photogrammetric Engineering and Remote Sensing, 68:607-621.

Ülker, D., Ergüven, O., Gazioğlu, C. (2018). Socioeconomic impacts in a Changing Climate: Case Study Syria, International Journal of Environment and Geoinformatics, 5(1), 84-93, doi.10.30897/ ijegeo.406273

Wanner, W., Strahler, A. H., Hu, B., Lewis, P., Muller, J.P., Li, X., Schaaf, C. B., Barnsley, M. J.(1997). Global retrieval of bidirectional reflectance and albedo over land from EOS MODIS and MISR data: Theory and algorithm, Journal of Geophysical Research, 102, 17,143-17,161.

Yang, R. Q., M. Friedl, Ni, W. (2001). Parameterization of shortwave radiation fluxes for nonuniform vegetation canopies in land surface models. Journal of Geophysical Research, 106, 14275-14286. 